Article

\title{
A Global Dynamic Harmony Search for Optimization of a Hybrid Photovoltaic-Battery Scheme: Impact of Type of Solar Panels
}

\author{
Jingchao Liu ${ }^{1}$, Lixue Mei ${ }^{2}$, Akbar Maleki ${ }^{3, *(\mathbb{D},}$, Roghayeh Ghasempour ${ }^{4}$ and Fathollah Pourfayaz ${ }^{4}(\mathbb{D}$ \\ 1 Department of Mechanical and Electrical Technology, Xijing University, Xi'an 710123, China; \\ liujingchaoxijing@126.com \\ 2 College of Mechanical Electronic Engineering, Jingdezhen University, Jingdezhen 333000, China; \\ 1xmei_7259@126.com \\ 3 Faculty of Mechanical Engineering, Shahrood University of Technology, Shahrood 3619995161, Iran \\ 4 Department of Renewable Energies, Faculty of New Science \& Technologies, University of Tehran, \\ Tehran 1439957131, Iran; ghasempour86@gmail.com (R.G.); pourfayaz@ut.ac.ir (F.P.) \\ * Correspondence: a_maleki@shahroodut.ac.ir or akbar.maleki20@yahoo.com
}

check for updates

Citation: Liu, J.; Mei, L.; Maleki, A.; Ghasempour, R.; Pourfayaz, F. A

Global Dynamic Harmony Search for Optimization of a Hybrid

Photovoltaic-Battery Scheme: Impact of Type of Solar Panels. Sustainability 2022, 14, 109. https://doi.org/ $10.3390 /$ su14010109

Academic Editor: Xiaosong Hu

Received: 27 November 2021

Accepted: 8 December 2021

Published: 23 December 2021

Publisher's Note: MDPI stays neutral with regard to jurisdictional claims in published maps and institutional affiliations.

Copyright: (c) 2021 by the authors. Licensee MDPI, Basel, Switzerland. This article is an open access article distributed under the terms and conditions of the Creative Commons Attribution (CC BY) license (https:// creativecommons.org/licenses/by/ $4.0 /)$.

\begin{abstract}
The type of solar panels has a great impact on the optimal sizing of a hybrid photovoltaicbattery scheme. The optimization of these schemes based on a powerful optimization approach results in more cost-effective schemes. In this paper, a new global dynamic harmony search method, as an optimization method, is presented for the optimal sizing of a hybrid photovoltaic-battery scheme. The new optimization method is aimed at minimizing the total cost and loss of load supply probability of the scheme at the same time. In this regard, the effect of the type of solar panels on the optimal sizing of the hybrid scheme is investigated. Furthermore, performance optimizations are performed with an original global dynamic harmony search, an original harmony search, and simulated annealing to determine the effectiveness of the suggested optimization method. The effects of the initial costs and efficiency of monocrystalline and polycrystalline solar panels on the optimization of hybrid systems are analyzed. The superiority of the suggested method in terms of time and cost indicators of the hybrid scheme is presented comparing the other algorithm.
\end{abstract}

Keywords: hybrid photovoltaic-battery system; optimal sizing; global dynamic harmony search algorithm; type of PV panels; cost-effective and reliable system

\section{Introduction}

Renewable energies, as one of the alternative energy sources of fossil fuels, have attracted many researchers as a source of endless energy in the world [1,2]. Among the renewable energies, solar energy has received wide attention and research in the world in recent years. The vigorous development of solar power generation can slow down the consumption of fossil fuels and is of great significance to reduce environmental pollution. Solar energy sources, especially PV panel systems, are applicable for off-grid and ongrid power generation. PV panel systems are suitable for supplying the load demand in stand-alone and remote areas as a clean and cost-effective system [3].

However, due to the uncontrollability and randomness of solar energy, solar power generation makes it difficult to meet the load demand in remote areas, which brings great challenges to the reliable and safe operation of solar power generation systems. To solve this problem, it is necessary to use energy storage and backup units. In this regard, battery energy storage is usually used for electricity storage in remote areas as a backup system [4-11]. Therefore, the hybrid photovoltaic-battery scheme is suggested for the reliable and safe operation of solar power generation systems in remote areas [12-15].

In order to improve the utilization efficiency of solar energy and realize the costeffective, safe, and reliable operation of hybrid photovoltaic-battery systems, it is necessary 
to provide accurate modeling and powerful optimization algorithm. At the same time, using a suitable solar panel is beneficial to hybrid photovoltaic-battery systems. The photovoltaic panel systems can fit into three categories: monocrystalline (Mono-SI), polycrystalline (Poly-SI), and thin-film PV panels. Mono-SI panels have the highest efficiency (16.5-24\%) in direct sunlight and are the most expensive and spatially efficient. Polycrystalline panels have lower prices and efficiency (about 12-16\%) compared to Mono-SI panels and lower spatial efficiency. Thin-film solar panels are the cheapest and least efficient (about 6-8\%) compared to the others [16]. Thus, Mono-SI and Poly-SI solar panels are suggested for the reliable and safe operation of the hybrid photovoltaic-battery system in remote areas.

In recent years, experts have done much research on the investigation of hybrid schemes with solar energy. Symeonidou et al. [17] presented a mathematical tool to manage the energy produced by the residential on-grid hybrid photovoltaic-battery system. It is found that storage is a feasible selection whenever selling power to the main grid is not appropriate. Karamov and Suslov [18] presented a methodology based on the Chronological modeling method for optimization of the stand-alone hybrid photovoltaicbattery scheme. It is found that the combined use of photovoltaics and batteries reduces diesel fuel consumption by $51 \%$. Bhayo et al. [19] used a particle swarm optimization (PSO) technique for the optimization of an off-grid photovoltaic-battery-hydro scheme for powering a $3.032 \mathrm{kWh} /$ day housing unit. It is found that the hybrid scheme is matching to meet the load demand in the remote area. Anoune et al. [20] used a genetic algorithm for optimal sizing and techno-economic analysis of the hybrid solar-wind-battery system in the International University of Rabat, Morocco, to minimize the total costs and the loss of power supply probability. It is found that the lowest loss of the power supply probability ratio corresponds to the higher total cost value and the opposite, too. Ridha et al. [21] presented a multi-objective optimization and techno-economic analysis for the optimal size of the off-grid hybrid photovoltaic-battery scheme through reliability and cost assessments. In this regard, the hybrid scheme performance was analyzed based on different kinds of batteries. It is found that the optimal configuration of the hybrid photovoltaic-battery scheme based on a lead-acid battery has less fitness function (total cost and loss of load). So, the hybrid scheme based on lead-acid batteries can be appropriate for real-world applications. Khan and Javaid [22] presented an optimization technique based on Jaya Learning for hybrid photovoltaic-wind-battery systems to provide electricity in remote areas, based on the minimum total annual cost and satisfying the reliability of the scheme. It is found that the hybrid photovoltaic-wind-battery systems are the most economical scenario. Bukar et al. [23] used a grasshopper optimization method for optimal sizing of off-grid photovoltaic-wind-battery-diesel microgrid. The proposed algorithm is applied to minimize the total cost and maximize scheme reliability. Fodhil et al. [24] used an approach based on the PSO for the optimization of the PV-diesel-battery scheme for rural areas. It is found that the PSO algorithm is more cost-effective than the HOMER software. Koskela et al. [25] presented a theory of sizing for the profitability of a hybrid photovoltaicbattery system based on electricity cost optimization in an apartment building in Finland. It is found that the optimal size of the PV scheme could be increased by using a battery bank and appropriate electricity pricing. Tu et al. [26] used a model based on mixed-integer linear programming to minimize the total cost for a stand-alone photovoltaic-wind-dieselbattery scheme. Kazem et al. [27] used a method for the optimal sizing of a stand-alone hybrid photovoltaic-battery in terms of system availability and cost for remote areas in Oman. Dai et al. [28] used an optimization model based on a PSO algorithm for the optimal sizing of an on-grid hybrid photovoltaic-battery-electric vehicle charging station in Shanghai, China. The results show that the optimization method based on PSO can improve the accuracy of the results and achieve rapid convergence. Cai et al. [29] presented an optimization strategy based on a geographic information system for the optimal sizing and location for a hybrid photovoltaic-battery-diesel system in rural areas. It is found that the use of the hybrid photovoltaic-battery-diesel scheme significantly reduces supply 
costs and gas emissions. Maleki et al. [30] used a harmony search (HS) algorithm for the optimal sizing of the hybrid photovoltaic-battery systems to provide essential electricity in a remote area. It is found that using harmony search leads to more promising results. Alshammari and Asumadu [31] used an algorithm based on HS for the optimum unit sizing of the hybrid photovoltaic-wind-battery-biomass scheme based on the lowest cost in a remote area. It is found that the hybrid algorithm based on HS optimizes the hybrid photovoltaic-biomass-wind-battery system with the lowest cost and best performance. Chauhan and Saini [32] used the discrete harmony search method for optimal sizing of the off-grid energy scheme based on a solar-wind-battery system for remote rural regions in India. It is found that the HS method is promising for the optimization of the hybrid system. In this regard, the HS algorithm is one of the powerful methods that have been considered for optimizing hybrid energy systems [33-35].

However, the above research uses different optimization algorithms and shows that the HS method is promising for the optimization of the hybrid system but does not use the global dynamic HS method. In this regard, the HS method has disadvantages, including the local optima problem (or becoming stuck in local optima), that have not been addressed. In optimization problems, the local optima are defined as the relative best solutions within a neighbor solution set. Different hybrid solar systems are optimized to meet the load, but the reliability is poor. In addition, the effect of the type of solar panel is not considered in the optimization, and the effects of the initial costs and efficiency of monocrystalline and polycrystalline solar panels are not extracted for the optimization of hybrid systems. Based on the above analysis, in order to identify cost-effective, safe, and reliable operation of power generation systems in remote areas, this paper proposes a new global dynamic harmony search (GDHS-I) algorithm as an optimization algorithm for the optimal sizing of a hybrid photovoltaic-battery scheme. The hybrid photovoltaic-battery scheme is optimized based on different types of solar panels (monocrystalline and polycrystalline). In this regard, the performance optimizations are performed with the original GDHS, original HS, and simulated annealing (SA) to determine the effectiveness of the GDHS-I algorithm. Finally, the effect of initial costs and the efficiency of monocrystalline and polycrystalline solar panels on the optimization of hybrid systems is analyzed. The main contributions of this study in analyzing the performance of hybrid photovoltaic-battery scheme are as follows:

- Introducing a global dynamic harmony search method to perform optimization and to determine the optimal sizing of a hybrid photovoltaic-battery system;

- To determine the effectiveness of the suggested optimization method, the performance optimizations are performed with original global dynamic harmony search, original harmony search, and simulated annealing;

- Based on indicators such as minimizing total cost and loss of load supply probability, the features of the solar panels on the optimal sizing of the hybrid scheme are investigated to determine the best solar panel subsystem selection;

- Sensitivity analysis is conducted on the optimized hybrid systems to test the influence of various initial costs and efficiency of monocrystalline and polycrystalline solar panels.

In the next section, the modeling of the hybrid photovoltaic-battery scheme is given. In Section 3, the objective function is presented. Section 4 gives a detailed methodology of this study. Section 5 illustrates the results and discussion. Section 5 is the conclusion of this article.

\section{Modeling of the Hybrid Photovoltaic-Battery Scheme}

In this study, optimal sizing of the hybrid photovoltaic-battery scheme to the costeffective, safe, and reliable operation of power generation systems in remote areas is considered. Figure 1 shows the general configuration of the hybrid PV-battery scheme. Different types of PV panels and batteries are connected through a DC bus, whereas the load is connected through an AC bus in this planning. The produced power from the 
hybrid photovoltaic-battery system is converted through DC/AC inverter to meet the load demand.

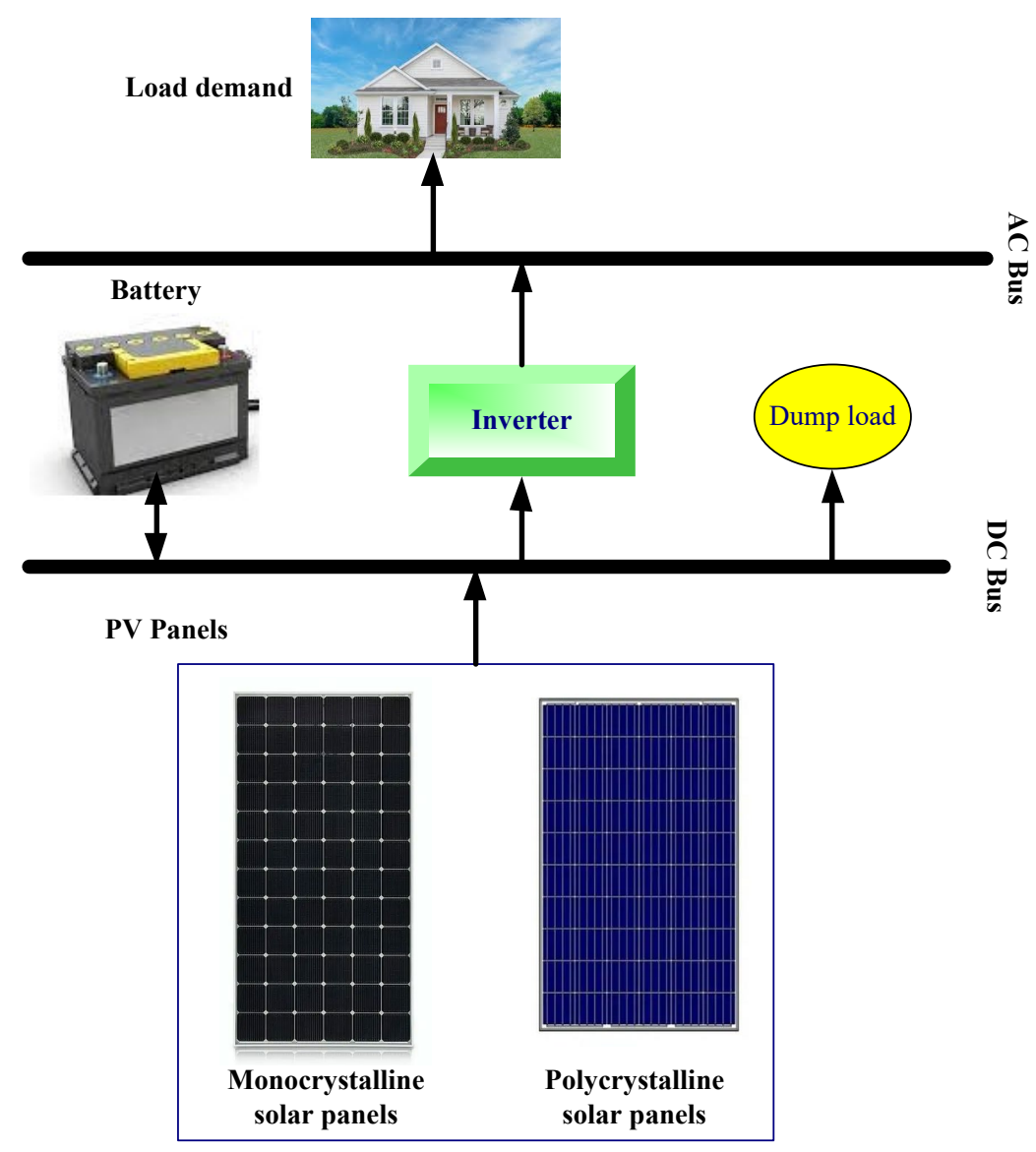

Figure 1. General configurations of the hybrid photovoltaic-battery system.

\subsection{Photovoltaic}

The generated power of the PV array $\left(p_{P V}\right)$ based on solar radiation on a tilted plane module $R_{t}\left(\right.$ in $\left.\mathrm{kW} / \mathrm{m}^{2}\right)$, the efficiency of the PV panels, and the cell temperature $T e_{\mathcal{C}}\left({ }^{\circ} \mathrm{C}\right)$ can be determined according to the following equations [36,37]:

$$
\begin{gathered}
p_{P V}(t)=R_{t} \eta_{P V} A_{P V} \\
\eta_{P V}=\eta_{r} \eta_{p c}\left[1-N_{T e}\left(T e_{c}-T e_{r e f}\right)\right] \\
T e_{c}=T e_{a i r}+\left[\frac{N O C T-20}{800}\right] R_{t}
\end{gathered}
$$

where $A_{P V}$ denotes the area of the PV panels (in $\left.\mathrm{m}^{2}\right), \eta_{r}$ and $\eta_{p c}$ denote the reference module efficiency and the power conditioning efficiency, respectively, $T e_{r e f}$ and $T e_{\text {air }}$ refer to the cell temperature at the reference conditions and ambient air temperature, $N_{T e}$ is the panel temperature coefficient, and NOCT is the nominal cell operating temperature, which is measured under $20^{\circ} \mathrm{C}$ of ambient temperature, $1 \mathrm{~m} / \mathrm{s}$ wind speed, and $800 \mathrm{~W} / \mathrm{m}^{2}$ of solar radiation.

\subsection{Storage System}

The hybrid power generation system based on PV panels needs storage units as a back-up system to supply the electrical demand at lacking PV power generation times. The energy storage level (ESL) of the battery unit is acquired as follows [38,39]: 
In charging mode:

$$
E S L(t)=E S L(t-1) \cdot(1-\sigma)+\left[\left(E_{P V}(t) \cdot \eta_{I N V}\right)-\frac{E_{L o a d}(t)}{\eta_{I N V}}\right] \cdot \eta_{B C}
$$

In discharging mode:

$$
E S L(t)=E S L(t-1) \cdot(1-\sigma)-\left[\frac{E_{\text {Load }}(t)}{\eta_{I N V}}-\left(E_{P V}(t) \cdot \eta_{I N V}\right)\right] / \eta_{B D C}
$$

where $\sigma$ denotes the rate of hourly self-discharge; $\eta_{I N V}, \eta_{B C}$, and $\eta_{B D C}$ are the efficiency of the inverter, charging, and discharging modes, respectively; and $E_{\text {Load }}$ represents the demand of load at time $t(1 \mathrm{~h})$.

\section{Objective Function}

The considered objective function in the current paper is the total net annual cost (TNAC) minimization based on the loss of load supply probability (LLSP) as a reliability index to find the ideal sizing of the hybrid photovoltaic-battery scheme.

\subsection{LLSP}

To have an organization with acceptable reliability, LLSP is applied, which shows how often the hybrid photovoltaic-battery scheme is inefficient in meeting the load demand [40-42]. The following equation is used for finding LLSP for one year $(8760 \mathrm{~h})$ :

$$
\text { LLSP }=\frac{\sum_{t=1}^{t=8760} \operatorname{LLS}(t)}{\sum_{t=1}^{t=8760} E_{\text {Load }}(t)}
$$

Here, LLS denotes the loss of load supply whenever the energy demand is more than the energy produced $\left(E_{G e n}\right)$ :

$$
L L S(t)=E_{\text {Load }}(t)-E_{G e n}(t)
$$

\subsection{TNAC}

TNAC includes the annual operation and maintenance cost (O\&M) and annual capital and replacement cost (C\&R). In the optimization process, the TNAC must be minimized as an objective function:

$$
\text { Minimize.TNAC }=\sum C \& R+O \& M
$$

By recognizing the project lifetime, replacement periods, annualized O\&M costs, and annualized $C \& R$ costs for each component of the hybrid photovoltaic-battery system, the TNAC value can be determined according to the following equations:

$$
\begin{gathered}
C \& R=C R F \cdot\left[A_{P V} \cdot C \& R_{P V}+N_{B S} \cdot C \& R_{B S}+N_{I N V} \cdot C \& R_{I N V}\right] \\
O \& M=A_{P V} \cdot O \& M_{P V}+N_{B S} \cdot O \& M_{B S}+N_{I N V} \cdot O \& M_{I N V}
\end{gathered}
$$

where $N_{I N V}$ and $N_{B S}$ denotes the number of inverter and battery, $C \mathcal{E} R_{P V}$ is the PV panel unit cost, $C \mathcal{E} R_{B S}$ is the present worth of battery based on life span of battery (here, 5 years), $C \mathcal{E} R_{I N V}$ is the present worth of converter/inverter based on its life span (here 10 years), $O \mathcal{E} M_{P V}, O \mathcal{E} M_{B S}, O \mathcal{E} M_{I N V}$ denote the O\&M costs of the PV panel, battery, and inverter/converter unit, respectively, and CRF represents the capital recovery factor, which is defined by the following equation based on the interest rate (i) and project life span (n) [43]:

$$
C R F=\frac{i(1+i)^{n}}{(1+i)^{n}-1}
$$




\subsection{Constraints}

The optimization algorithm is working according to the highest allowable value of LLSP (here, 2\%) [40-42] and other limitations of the decision variables (area of the PV panel and number battery):

$$
\begin{gathered}
L L S P \leq 2 \% \\
0 \leq A_{P V} \leq A_{P V-M a x} \\
0 \leq N_{B S} \leq N_{B S-M a x} \\
E S L_{M i n} \leq E S L \leq E S L_{M a x} \\
E S L_{M i n}=(1-D O D) \cdot S_{B S}
\end{gathered}
$$

where $N_{B S-M a x}$ and $A_{P V-M a x}$ refer to the maximum area of the PV panels and the maximum number of batteries, respectively, $E S L_{M i n}$ and $E S L_{M a x}$ are the minimum and maximum energy storage levels of the battery bank, respectively, and $S_{B A}$ and DOD are the nominal capacity of battery and depth of discharge, respectively.

\subsection{Operation Strategy}

The operation strategy used in the proposed hybrid photovoltaic-battery system is presented in Figure 2. So, the calculation of the total power production by PV panels and the calculation of the energy storage in storage units as a back-up system to supply the electrical demand at lacking PV power generation times is performed through the loop below during a year $(8760 \mathrm{~h})$. Here, $j$ is the number of the configuration of the hybrid system, which is determined based on the maximum number of PV panels, batteries, and the maximum number of iterations in the optimization algorithm.

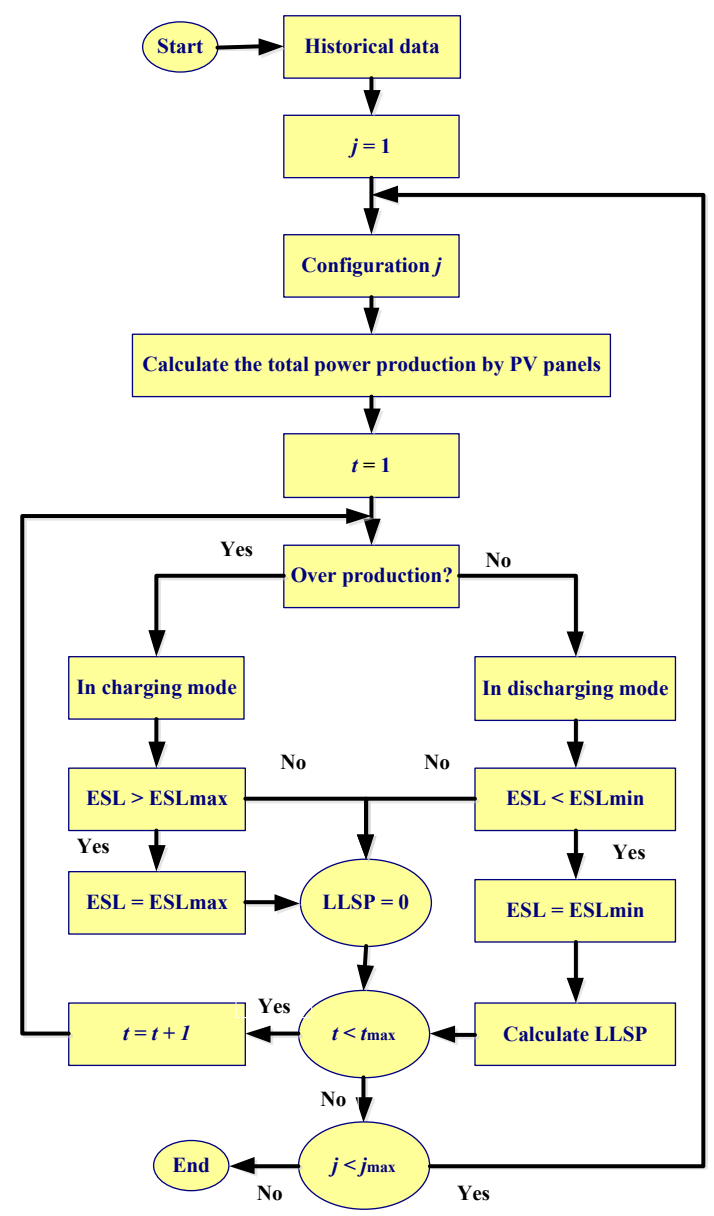

Figure 2. The operation strategy of the hybrid photovoltaic-battery system. 


\section{Methodology}

Considering the discrete (integer) and continuous nature of decision variables in a size optimization problem, an efficient search technique based on the Harmony Search (HS) is implemented to solve this type of sizing problem.

\subsection{Harmony Search (HS)}

The HS is an optimization algorithm suggested by Geem et al. [44] in 2001. In this regard, discrete HS, which was proposed by Maleki et al. [45], tends to result in more accurate results when compared with discrete simulated annealing. Harmoney Memory Considering Rate (HMCR), pitch adjustment rate (PAR), and bandwidth of generation (BG) are parameters that are pivotal in the converging process of the aforementioned HS method. These parameters are critically important in providing the algorithm with an optimal solution and speed at which this solution is obtained. The rate at which a value is selected from the Harmony Memory varies between 0 and 1 and is called HMCR. Memory consisting of $N_{h}$ harmonies is called Harmony Memory. A trial-and-error process was utilized to determine the algorithm parameters, and PAR, HMCR, and BG of the HS algorithm in this process were set to $0.3,0.9$, and 0.03 , respectively.

Below are the steps required to generate a new harmony via HS:

Step 1: A uniformly distributed random number is generated between 0 and 1 . If the aforementioned number has a greater value than HMCR, the production of the improvised note is going to be random and from the possible range. In addition, the following note is going to be improvised, if not, proceed to Step 2.

Step 2: The value corresponding to the improvised note is a randomly selected note from the pool of HM. The next step is the generation of a uniformly distributed number between 0 and 1 . If the value of the aforementioned number is greater than PAR, no change to the value of the improvised note is required. If not, proceed to the third step.

Step 3: If the value of the improvised note is changed by BG, we move to a randomly selected direction via BG value.

If the quality of the newly generated harmony is higher than the worst HM harmony, the newly generated harmony is going to be stored while the worst harmony is removed from HM. This process continues to the point in which the maximum number of iterations is reached.

\subsection{Global Dynamic Harmonic Search Algorithm: GDHS}

In a recent study, a new HS algorithm was modified by Khalili [46], which was named GDHS. In this modified version of the algorithm, BG, PAR, and HMCR were adjusted via a dynamic approach. Furthermore, in the aforementioned method, the domain changed dynamically, a dynamic mode was introduced for all key parameters, and predefining the parameters was unnecessary. BG, PAR, and HMCR were mathematically expressed via the following formulas:

$$
\begin{aligned}
& B G(t)=B G_{\max } \mathrm{e}^{\left(\frac{L n\left(B G_{\min } / B G_{\max }\right)}{\text { iter } \max _{\max }} \times i t e r\right)} \\
& \operatorname{HMCR}(t)=0.9+0.2 \times \sqrt{\frac{\text { iter }-1_{\text {iter }_{\max }-1} \times\left(1-\frac{\text { iter }-1}{\text { iter }_{\max }-1}\right)}{}} \\
& \operatorname{PAR}(t)=0.85+0.3 \times \sqrt{\frac{\text { iter }-1}{\text { iter }_{\max }-1} \times\left(1-\frac{\text { iter }-1}{\text { iter }_{\max }-1}\right)}
\end{aligned}
$$

In the above correlations, iter $_{\max }$ stands for the maximum number of iterations, iter indicates the current iteration, and $B G_{\min }$ and $B G_{\max }$ are the symbolic representations of the minimum and the maximum band with values, respectively.

New Harmony is found by applying the following relation:

$$
x_{n e w, j}=x_{n e w, j}+B G \times(\text { rand }-0.5) \cdot\left(x_{\text {best }, j}-x_{n e w, j}\right)
$$




\subsection{GDHS-I}

Considering the prevention of local optima, this section is dedicated to introducing the newly developed GDHS algorithms incorporating the pitch adjustment mechanism, namely, the GDHS-I algorithm. New Harmony is found by applying the following relation:

$$
x_{n e w, j}=x_{n e w, j}+\text { rand } \times \cdot \alpha \cdot\left(x_{b e s t, j}-x_{n e w, j}\right)
$$

In the aforementioned formula, $\alpha$ represents the weighting factor, which is selected based on hybrid system components, where $x_{\text {best }}$ shows the best harmony.

Figure 3 is a representation of the computational procedure in this novel GDHS algorithm.

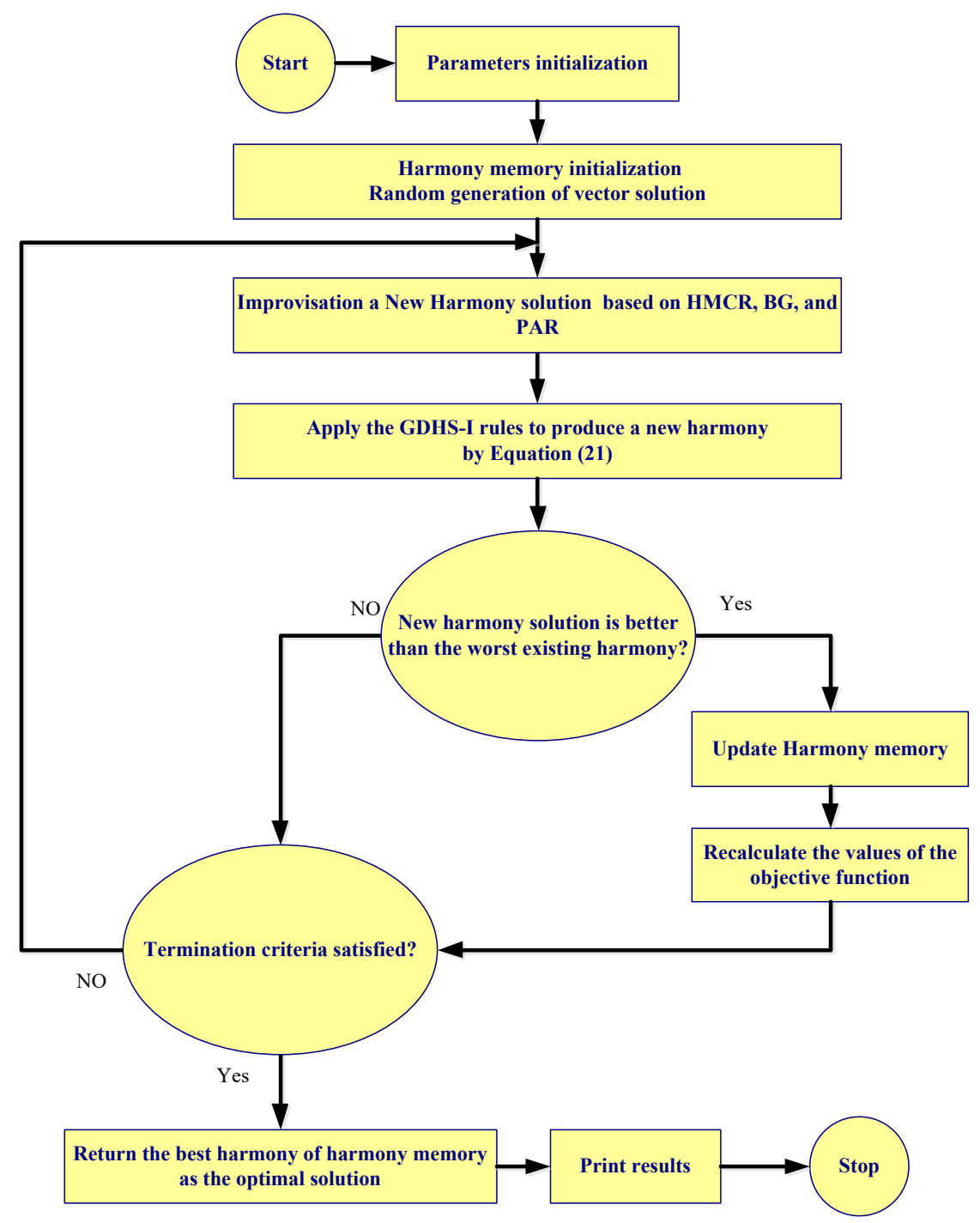

Figure 3. Flowchart of the GDHS-I algorithm.

\section{Results and Discussion}

In this section, the results obtained by applying the suggested optimization algorithm (new global dynamic harmony search (GDHS-I)) to the hybrid photovoltaic-battery system will be presented. Furthermore, performance optimizations are performed with the original GDHS [47], original HS [48], and simulated annealing [49] to determine the effectiveness of the GDHS-I method. MATLAB software is used to implement the suggested optimization methods on a computer PC (core-i7, 6 GB RAM, and $2.3 \mathrm{GHz}$ CPU). The used optimization model is measured to achieve a case study in Rafsanjan $\left(30^{\circ} 24^{\prime} 24^{\prime \prime} \mathrm{N} 55^{\circ} 59^{\prime} 38^{\prime \prime} \mathrm{E}\right)$, Iran. For this purpose, the parameters of the stand-alone hybrid system are presented in Table 1, and 
the parameters of the optimization algorithms are given in Table 2 [37,50-53]. In addition, the typical load demand, solar insolation, and ambient temperature during a year $(8760 \mathrm{~h})$ are used in this study, which are given in Figure 4.

Table 1. Parameters of the hybrid system components.

\begin{tabular}{|c|c|}
\hline \multicolumn{2}{|c|}{ Economic } \\
\hline$r$ & $10 \%$ \\
\hline$n$ & 20 years \\
\hline \multicolumn{2}{|c|}{ PV Panel } \\
\hline Life Span & 25 \\
\hline$C \mathcal{E} R_{P V}$ (Mono-SI) & $210 \mathrm{USD} / \mathrm{m}^{2}$ \\
\hline$C \mathcal{E} R_{P V}($ Poly-SI $)$ & $120 \mathrm{USD} / \mathrm{m}^{2}$ \\
\hline$O \mathcal{E} M_{P V}$ & $2 \% C_{P V} \mathrm{USD} / \mathrm{m}^{2} /$ year \\
\hline Efficiency (Mono-SI) & $20 \%$ \\
\hline Efficiency (Poly-SI) & $15 \%$ \\
\hline \multicolumn{2}{|c|}{ Battery } \\
\hline$S_{B A}$ & $2.1 \mathrm{kWh}$ \\
\hline$\eta_{B C}$ & $85 \%$ \\
\hline$P_{B S}$ & USD 310 \\
\hline Life span & 5 years \\
\hline DOD & $80 \%$ \\
\hline$\omega$ & $0.02 \%$ \\
\hline$O \mathcal{E} M_{B S}$ & 10 USD/year \\
\hline \multicolumn{2}{|c|}{ Converter/Inverter } \\
\hline Rated power & $3 \mathrm{~kW}$ \\
\hline$\eta_{I N V}$ & $95 \%$ \\
\hline Life span & 10 years \\
\hline$P_{I N V}$ & USD 1583 \\
\hline$O \mathcal{E} M_{I N V}$ & 15 USD/year \\
\hline
\end{tabular}

Table 2. Parameters of the optimization algorithms.

\begin{tabular}{cccccccc}
\hline \multicolumn{2}{c}{ Harmony Search (HS) } & \multicolumn{2}{c}{$\begin{array}{c}\text { Global Dynamic HS } \\
\text { (GDHS) }\end{array}$} & \multicolumn{2}{c}{ GDHS-I } & \multicolumn{2}{c}{ SA } \\
\hline$H M C R$ & 0.9 & $B G_{\max }$ & 1 & $B G_{\max }$ & 1 & Step size & 0.97 \\
\hline PAR & 0.3 & $B G_{\text {min }}$ & 0.01 & $B G_{\min }$ & 0.01 & $\begin{array}{c}\text { Initial } \\
\text { temperature }\end{array}$ & 100 \\
\hline$B G$ & 0.03 & iter $_{\text {max }}$ & 2000 & $\alpha$ & 2 & iter $_{\text {max }}$ & 2000 \\
\hline iter $_{\text {max }}$ & 2000 & & & iter $_{\text {max }}$ & 2000 & & \\
\hline
\end{tabular}

As the harmony search method uses stochastic random searches in the search space, various runs may lead to finding various solutions. To solve this problem, the optimal solution is reported after several runs. In this regard, 30 independent runs for each algorithm (HS, GDHS, SA, and GDHS-I) are executed to provide valid results, and the optimal results are determined. These results for two types of solar panels (Poly-SI and Mono-SI) are reported in Table 3, which includes the average, worst (maximum), best (minimum), and standard deviation (Std.) of the TNAC value and the average simulation time indices. 


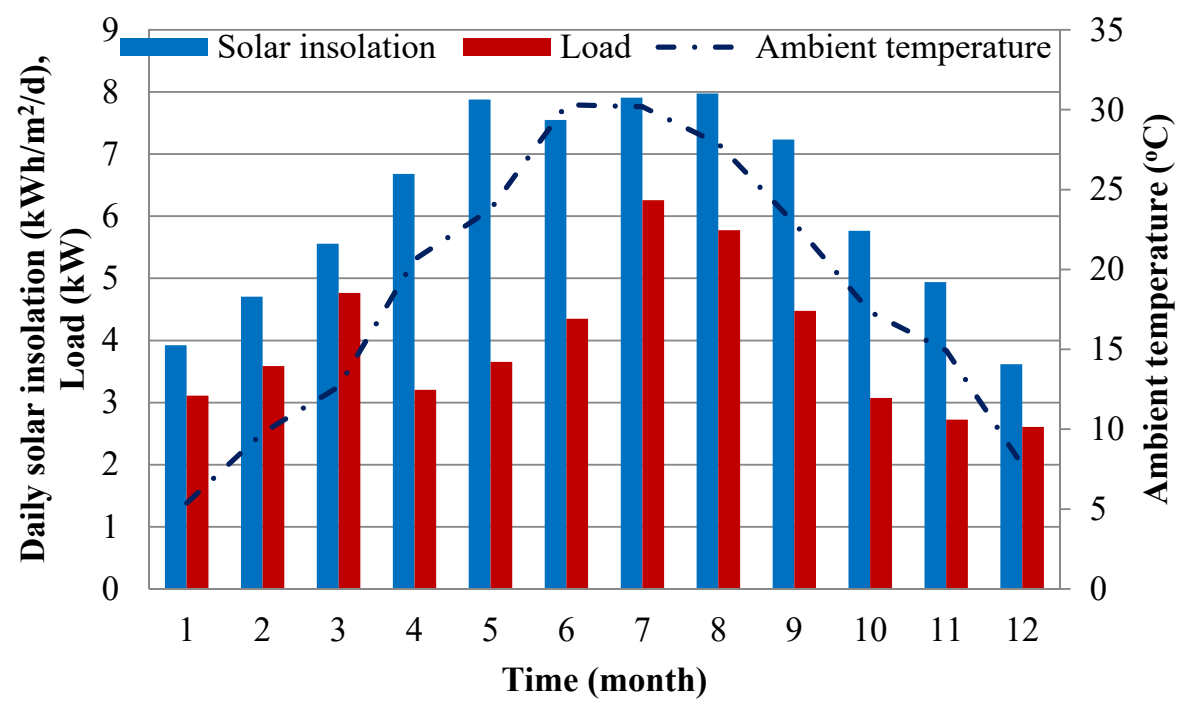

Figure 4. Typical load demand, solar insolation, and ambient temperature during a year.

Table 3. Results found by the studied algorithms for two types of solar panels.

\begin{tabular}{ccccccc}
\hline $\begin{array}{c}\text { Types of } \\
\text { Solar Panels }\end{array}$ & Algorithms $\backslash$ Index & $\begin{array}{c}\text { Best } \\
\text { (USD) }\end{array}$ & $\begin{array}{c}\text { Worst } \\
\text { (USD) }\end{array}$ & $\begin{array}{c}\text { Mean } \\
\text { (USD) }\end{array}$ & $\begin{array}{c}\text { Std. } \\
\text { (USD) }\end{array}$ & $\begin{array}{c}\text { Mean } \\
\text { Time (s) }\end{array}$ \\
\hline \multirow{3}{*}{ Poly-SI } & HS & 112,175 & 304,111 & 177,743 & 50,614 & 5.8604 \\
\cline { 2 - 6 } & GDHS & 109,907 & 260,735 & 160,051 & 33,593 & 5.8292 \\
\cline { 2 - 6 } & GDHS-I & 103,777 & 196,069 & 122,287 & 19,314 & 5.7495 \\
\hline \multirow{2}{*}{ Mono-SI } & SA & 223,570 & $1,795,007$ & $1,142,542$ & 439,224 & 13.6854 \\
\cline { 2 - 7 } & HS & 111,413 & 353,070 & 201,940 & 66,671 & 5.7229 \\
\cline { 2 - 6 } & GDHS & 105,580 & 291,204 & 162,397 & 49,245 & 5.7057 \\
\cline { 2 - 6 } & GDHS-I & 104,686 & 198,360 & 129,355 & 22,191 & 5.6776 \\
\hline
\end{tabular}

The optimization method is aimed at minimizing the TNAC value and the loss of load supply probability of the hybrid photovoltaic-battery system based on the optimum number of battery banks and area of the PV panels. The minimum bound of the battery banks and the area of the PV panels are set to 0 , and the maximum bound of the battery banks and the area of the PV panels are set to 20,000 and $350 \mathrm{~m}^{2}$, respectively. In Poly-SI solar panels, the best fitness function value of the photovoltaic-battery system is USD 103,777 , which is obtained by the GDHS-I algorithm. The subsequent ranks are displayed by GDHS, HS, and SA respectively. When utilizing the GDHS, HS, and SA methods, the minimum TNAC of the studied system is found to be USD 109,907, USD 112,175, and USD 223,570 , respectively. The relative error between the Best index of the GDHS-I and GDHS, $\left|\frac{\text { Best }_{G D H S-I}-\text { Best }_{G D H S}}{\text { Best }_{G D H S}-I}\right| \times 100$, is $5.9 \%$, and between the Best index of the GDHS-I and HS, it is $8.1 \%$. In addition, the relative error between the Mean index of GDHS-I and GDHS is $30.9 \%$, and between the Mean index of the GDHS-I and HS, it is $45.3 \%$. The best average simulation time value of the system is $5.7495 \mathrm{~s}$, which is obtained by the GDHS-I algorithm. The worst average simulation time value of the system is $13.6854 \mathrm{~s}$, which is obtained by the SA algorithm. Based on the mean and average simulation time indices, the result shows that the GDHS-I is better than the GDHS, HS, and SA methods (Figure 5). As a result, based on different indices (Best, Worst, Mean, Std., and Meantime), the GDHS-I method has more stoutness that the GDHS, HS, and SA methods, respectively. The convergence characteristics of the GDHS-I, GDHS, HS, and SA algorithms for Poly-SI solar panels are 
presented in Figure 6, which shows the superiority of GDHS-I in finding the best fitness function value.

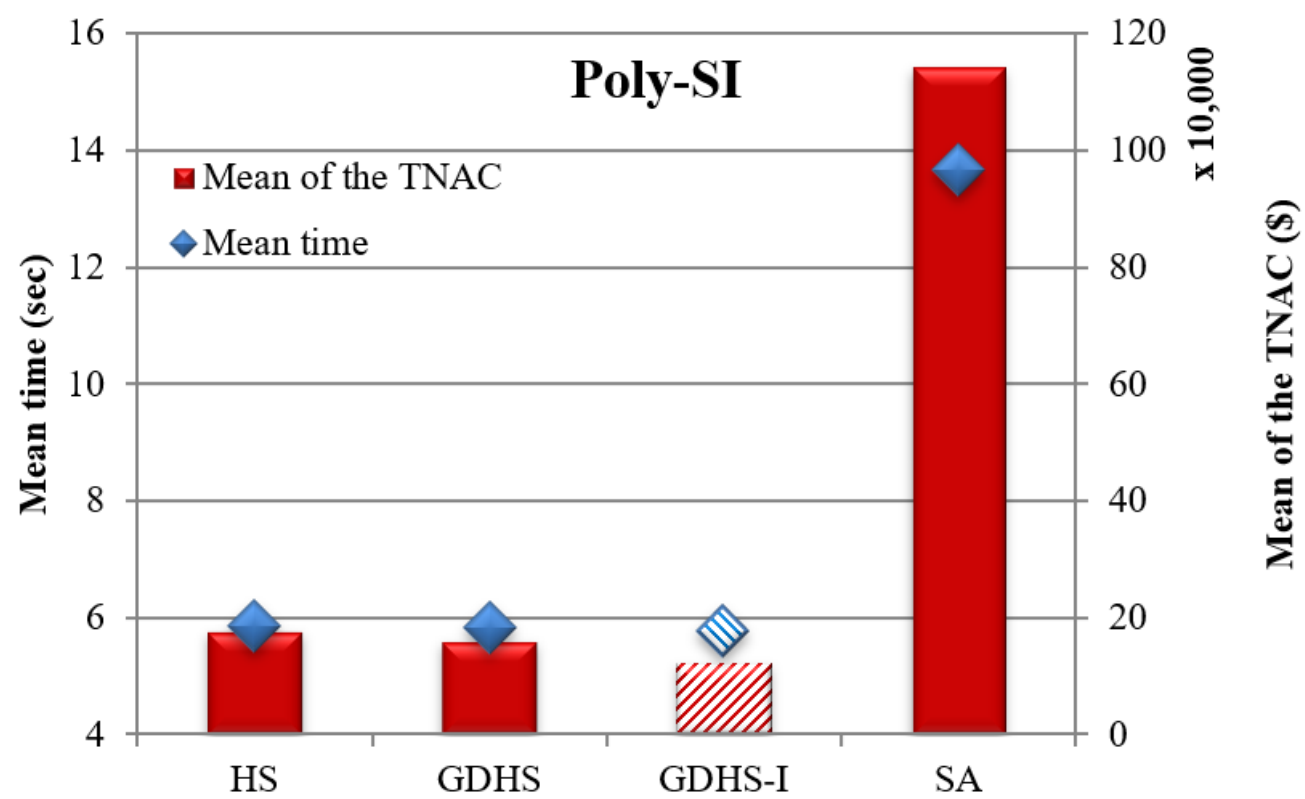

Figure 5. Mean simulation time and the mean of the TNAC values with suggested algorithms.

(a)

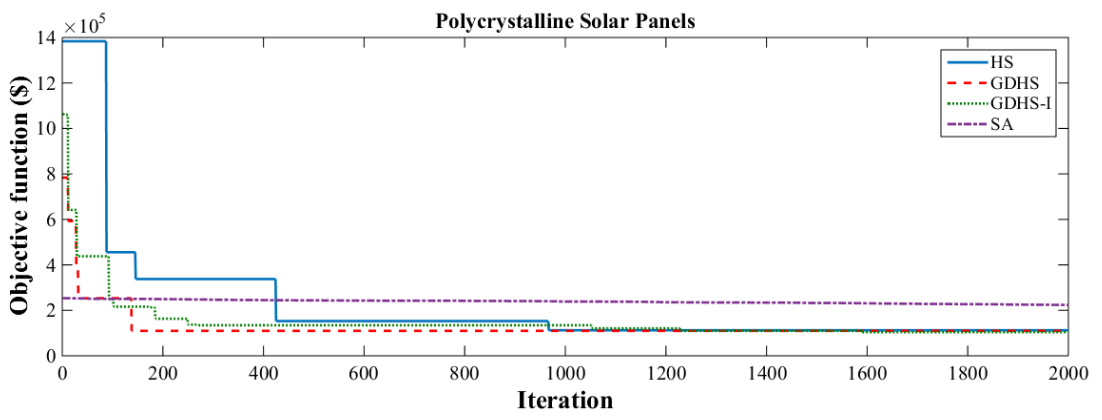

(b)

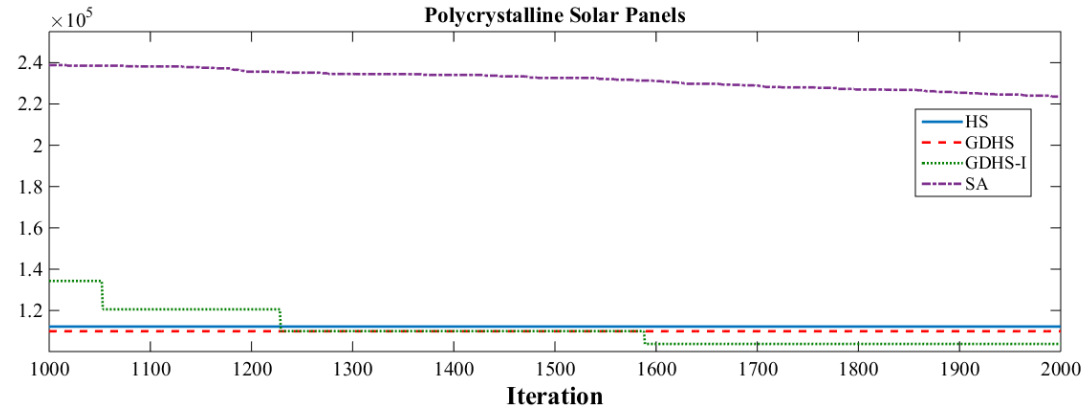

Figure 6. (a) The convergence characteristic of GDHS-I, GDHS, HS, and SA algorithms for Poly-SI solar panel; (b) zoomed in part.

In Mono-SI solar panels, the minimal TLCC, which denotes the optimal setup, is USD 104,686 , which is found by the GDHS-I algorithm. The subsequent ranks are displayed by GDHS (USD 105,580), HS (USD 111,413), and SA (USD 138,654), respectively. The relative error between the Best index of the GDHS-I and GDHS is $0.9 \%$; between the Best index of the GDHS-I and HS it is 6.4\%; and between the Best index of the GDHS-I and SA it is $32.45 \%$. In this case, the Mean, Worst, and Std. values of the fitness function are USD 129,355, USD 198,360, and USD 22,191, respectively, which are obtained by the GDHS-I algorithm. In this regard, the relative error between the Mean index of GDHS-I and GDHS is $25.5 \%$, and between the Mean index of the GDHS-I and HS it is $56.1 \%$. The mean simulation time 
value of the system is $5.6776 \mathrm{~s}$, which is obtained by the GDHS-I algorithm. The mean simulation time and the mean fitness function values with the proposed algorithms for Mono-SI solar panel are shown in Figure 7, which shows the superiority of GDHS-I based on the mean simulation time and the mean fitness function values. Figure 8 shows the convergence characteristic of the GDHS-I, GDHS, HS, and SA algorithms for the Mono-SI solar panels. It can be seen that the GDHS-I method is better than other methods in finding the best fitness function value.

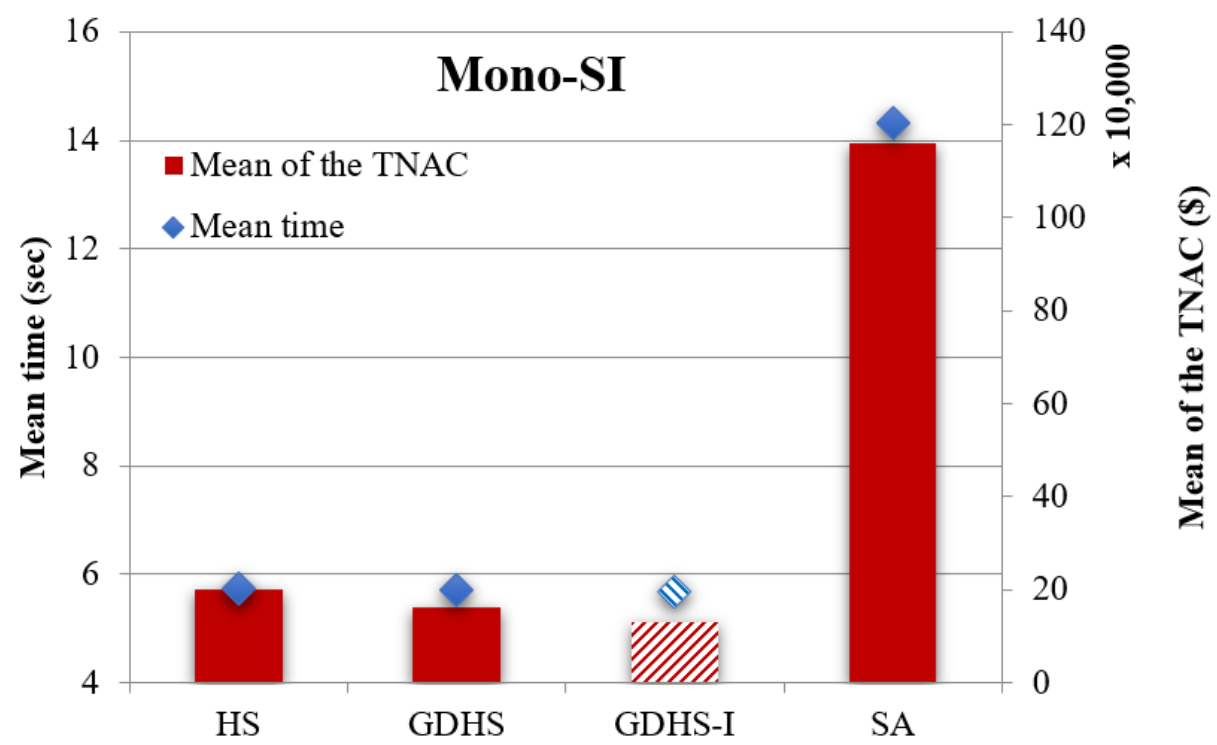

Figure 7. Mean simulation time and the mean of the TNAC values with suggested algorithms.

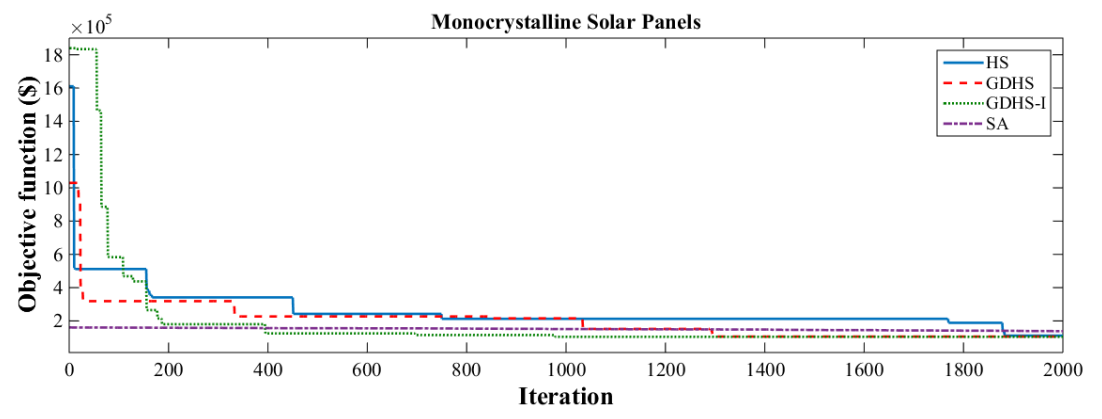

(b)

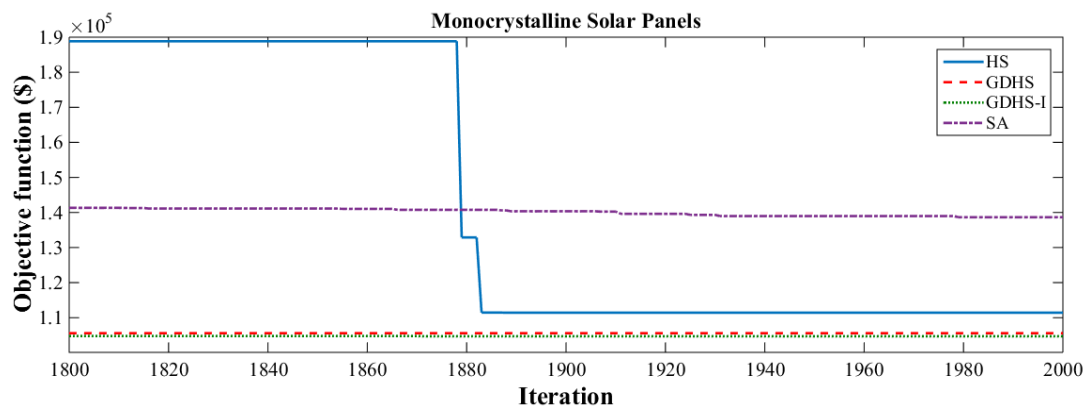

Figure 8. (a) The convergence characteristic of GDHS-I, GDHS, HS, and SA algorithms for Mono-SI solar panel; (b) zoomed in part.

To ensure the reliability of the GDHS-I method, the performance of the GDHS-I method is compared after the different number of runs (30 to 200) for two types of solar panels. The results found by the GDHS-I algorithm for the two types of solar panels for the different number of runs are presented in Table 4 . In this Table, the effect of the number of runs on the optimal system is investigated. In Poly-SI solar panels, when the number of runs is equal to 30 , the best fitness function value of the photovoltaic-battery system 
is USD103,777, which is similar to that found with 40 to 200 independent runs. In the Mono-SI Solar Panel, when the number of runs is equal to 30, the minimum TNAC of the studied system is USD 104,686. When the number of runs is equal to 30 to 200 , the minimum TNAC of the studied system (Best index) is the same.

Table 4. Results found by the GDHS-I algorithm for two types of solar panels for different number of runs.

\begin{tabular}{cccccc}
\hline Types of Solar Panels & Number of Runs & Best (USD) & Worst (USD) & Mean (USD) & Std. (USD) \\
\hline & 30 & 103,777 & 196,069 & 122,287 & 19,314 \\
\cline { 2 - 6 } Poly-SI & 40 & 103,777 & 161,764 & 119,379 & 13,304 \\
\cline { 2 - 6 } & 60 & 103,777 & 181,220 & 122,613 & 15,539 \\
\cline { 2 - 6 } & 100 & 103,777 & 162,999 & 119,525 & 12,029 \\
\cline { 2 - 6 } & 150 & 103,777 & 181,774 & 119,353 & 12,808 \\
\cline { 2 - 6 } & 200 & 103,777 & 210,169 & 119,495 & 13,921 \\
\cline { 2 - 6 } & 30 & 104,686 & 198,360 & 129,355 & 22,191 \\
\cline { 2 - 6 } & 40 & 104,686 & 170,772 & 122,140 & 14,352 \\
\cline { 2 - 6 } & 100 & 104,686 & 157,520 & 121,631 & 11,673 \\
\cline { 2 - 6 } & 150 & 104,686 & 184,150 & 121,195 & 14,619 \\
\hline
\end{tabular}

The optimal configurations of the hybrid photovoltaic-battery scheme for different types of solar panels (Poly-SI and Mono-SI) by the proposed algorithms are reported in Table 5. In Poly-SI solar panel, the optimal number of battery storage, and area of the PV panels, TNAC, and LLSP, found by GDHS-I, are 1088, $147 \mathrm{~m}^{2}$, USD103,777, and $1.9644 \%$, respectively. It is observed that when using GDHS, the values of TNAC and LLSP increase to USD109,907 and $1.9824 \%$, respectively. It can be seen that the values $A_{P V}$ and $N_{B S}$ are $146.2 \mathrm{~m}^{2}$ and 1155 in this case. When the HS algorithm is used, the optimal number of battery storage, and area of the PV panels, TNAC, and LLSP are 1179, $149.2 \mathrm{~m}^{2}$, USD112,175, and 1.5612\%, respectively. Also, when the SA algorithm is used, the optimal number of battery storage, and area of the PV panels, TNAC, and LLSP are $2395,139.4 \mathrm{~m}^{2}$, USD223,570, and $1.7805 \%$, respectively. The TNAC and LLSP values with GDHS-I, GDHS, HS, and SA algorithms for Poly-SI solar panels are shown in Figure 9. Among the results of the four algorithms, it is observed that the optimal configurations of the hybrid photovoltaic-battery scheme with the lowest cost (USD103,777) and appropriate reliability are obtained by the GDHS-I algorithm. In this regard, in the highest allowable value of LLSP (here $2 \%$ ), the GDHS-I shows approximately $5.6 \%$ \& $7.5 \%$ cost saving in comparison with the GDHS \& HS, respectively. Also, the GDHS-I shows approximately USD 119,793 cost saving in comparison with the SA algorithm.

In Mono-SI solar panel, the optimal values of $A_{P V}, N_{B S}$, TNAC, and LLSP are $110.1 \mathrm{~m}^{2}$, 1093, USD104,686, and 1.9924\%, respectively. They are found by the GDHS-I algorithm. Also, shows that the values of $A_{P V}, N_{B S}$, TNAC, and LLSP of the hybrid system are $110.2 \mathrm{~m}^{2}$, 1103 , USD105,609, and $1.9523 \%$, respectively by the GDHS algorithm. In this case, the optimal values of $A_{P V}$ and $N_{B S}$ are $109.9 \mathrm{~m}^{2}$ and 1166, respectively, by the HS algorithm. When the SA algorithm is used, the optimal values of $A_{P V}, N_{B S}$, TNAC, and LLSP of the hybrid system are $107.5 \mathrm{~m}^{2}, 1465$, USD138,654, and $1.9314 \%$, respectively. The TNAC and LLSP values with suggested algorithms for Mono-SI solar panel are shown in Figure 10. It can be seen that the GDHS-I algorithm with the lowest cost (USD 104,686) and appropriate reliability has superior robustness to the GDHS, HS, and SA methods due to its optimal values for the TNAC and LLSP. In this regard, in the highest allowable value of LLSP (here 2\%), the GDHS-I shows approximately USD 923, USD 6694, and USD 33,968 cost savings in comparison with the GDHS, HS, and SA, respectively. 
Table 5. Optimal configurations of the hybrid photovoltaic-battery scheme for different types of solar panels.

\begin{tabular}{cccccc}
\hline Types of Solar Panels & Algorithms $\backslash \mathbf{I n d e x}$ & $\boldsymbol{A}_{\boldsymbol{P V}}\left(\mathbf{m}^{\mathbf{2}}\right)$ & $\boldsymbol{N}_{\boldsymbol{B S}}$ & TNAC (USD) & LLSP (\%) \\
\hline \multirow{3}{*}{ Poly-SI } & HS & 149.2 & 1179 & 112,175 & 1.5612 \\
\cline { 2 - 5 } & GDHS & 146.2 & 1155 & 109,907 & 1.9824 \\
\cline { 2 - 5 } & GDHS-I & 147 & 1088 & 103,777 & 1.9644 \\
\cline { 2 - 5 } & SA & 139.4 & 2395 & 223,570 & 1.7805 \\
\hline \multirow{3}{*}{ Mono-SI } & HS & 109.9 & 1166 & 111,380 & 1.9241 \\
\cline { 2 - 5 } & GDHS & 110.2 & 1103 & 105,609 & 1.9523 \\
\cline { 2 - 5 } & GDHS-I & 110.1 & 1093 & 104,686 & 1.9924 \\
\hline & SA & 107.5 & 1465 & 138,654 & 1.9314 \\
\hline
\end{tabular}

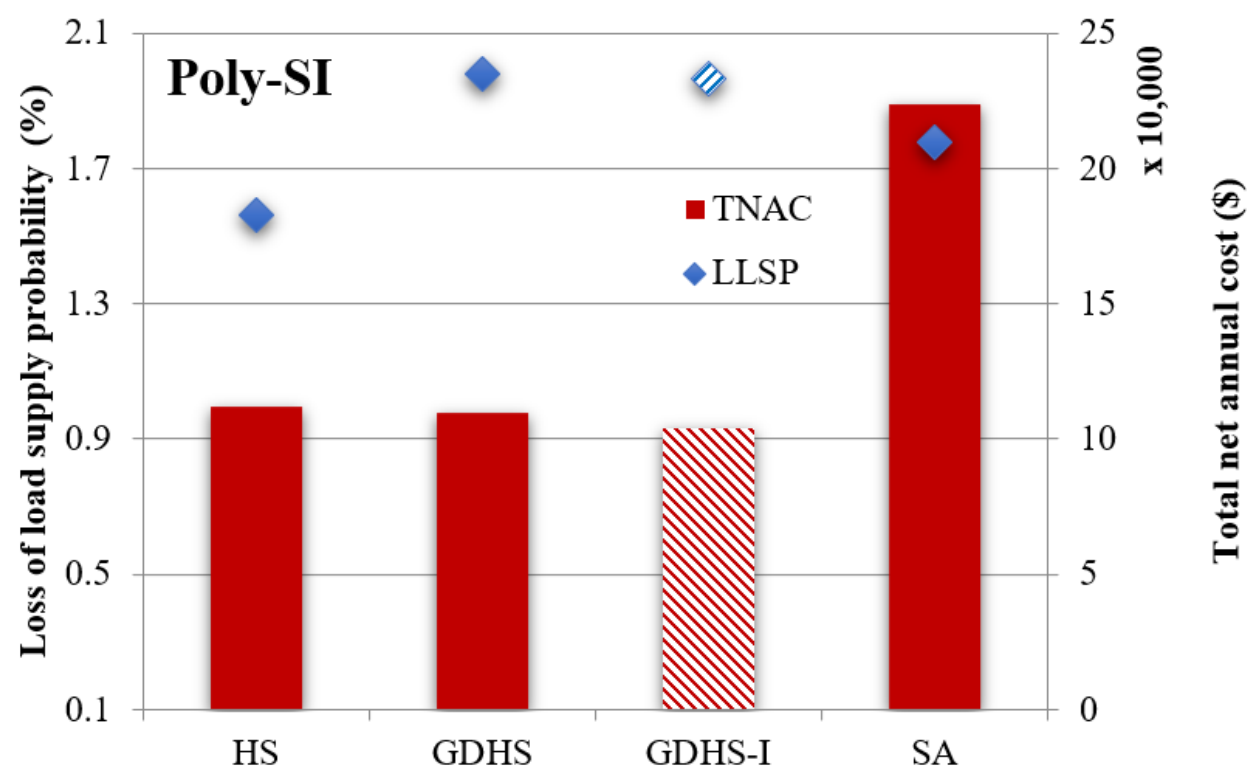

Figure 9. The TNAC and LLSP values with GDHS-I, GDHS, HS, and SA algorithms for Poly-SI solar panel.

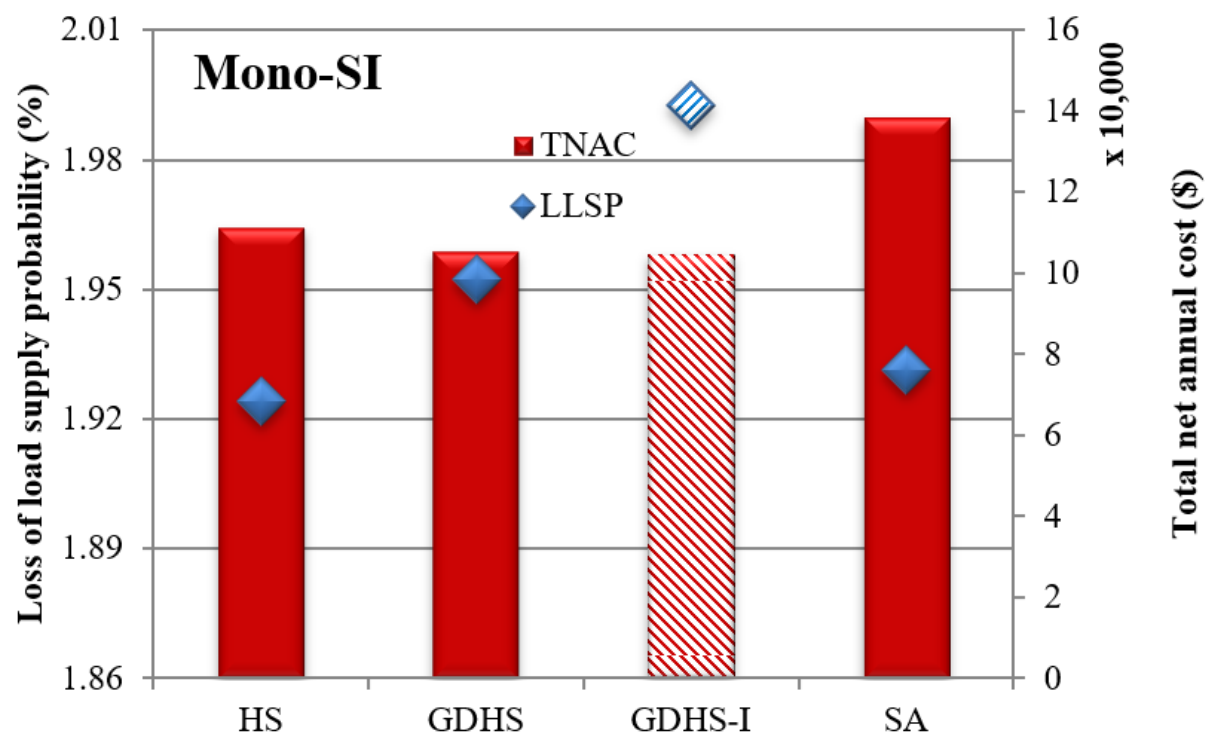

Figure 10. The TNAC and LLSP values with GDHS-I, GDHS, HS, and SA algorithms for Mono-SI solar panel. 


\section{Sensitivity Analysis}

In this section, first, the effect of the PV panel unit cost on the optimal system is investigated, and then the effect of the PV panel efficiency on the optimal hybrid system is analyzed. The optimal configurations of the hybrid photovoltaic-battery system for different types of solar panels for different PV panel unit costs are reported in Table 6. In Mono-SI solar panels, when the PV panel cost is equal to $210 \mathrm{USD} / \mathrm{m}^{2}$, the optimal values of the TNAC and LLSP of the hybrid scheme are USD 104,686 and $1.9924 \%$, respectively. In addition, the values of $A_{P V}$ and $N_{B S}$ are $110.1 \mathrm{~m}^{2}$ and 1093, respectively. When the PV panel cost is equal to $150 \mathrm{USD} / \mathrm{m}^{2}$ and $300 \mathrm{USD} / \mathrm{m}^{2}$, the optimal values of the TNACs of the hybrid system are USD 103,586 and USD 105,889, respectively. It is observed that by reducing the PV cost from $210 \mathrm{USD} / \mathrm{m}^{2}$ to $150 \mathrm{USD} / \mathrm{m}^{2}$, the value of the TNAC decreases to $1.1 \%$, and by increasing the PV cost from $210 \mathrm{USD} / \mathrm{m}^{2}$ to $300 \mathrm{USD} / \mathrm{m}^{2}$, the value of the TNAC increases to $1.2 \%$. In Poly-SI solar panels, when the PV panel cost is equal to $210 \mathrm{USD} / \mathrm{m}^{2}$, the optimal values of the TNAC and LLSP of the hybrid system are USD 106,167 and $1.9078 \%$, respectively. In addition, the values of $A_{P V}$ and $N_{B S}$ are $147.41 \mathrm{~m}^{2}$ and 1096, respectively. It is observed that by reducing the PV cost from $210 \mathrm{USD} / \mathrm{m}^{2}$ to $150 \mathrm{USD} / \mathrm{m}^{2}$, the value of TNAC decreases to USD 1120, and by increasing PV cost from $210 \mathrm{USD} / \mathrm{m}^{2}$ to $300 \mathrm{USD} / \mathrm{m}^{2}$, the value of TNAC increases to USD1470. As a result, by increasing the Mono-SI solar panel and Poly-SI solar panel unit costs, the TNAC of the hybrid system is increased (Figure 11). A comparison between the Mono-SI and Poly-SI solar panels shows that, at the same cost, the optimal values of $A_{P V}$ and TNAC of the hybrid system based on Poly-SI solar panels is more than the hybrid system based on Mono-SI solar panels. In other words, the hybrid system based on Mono-SI solar panels shows about a $37 \% A_{P V}$ saving in comparison with the hybrid system based on Poly-SI solar panels. In addition, the hybrid system based on Mono-SI solar panels shows about $1.5 \%$ cost savings in comparison with the hybrid system based on Poly-SI solar panels. The reason for the difference in cost, despite the same cost, is the difference in efficiency between the two panels.

Table 6. The optimal configuration of the hybrid photovoltaic-battery scheme for different types of solar panels for different PV panel unit cost.

\begin{tabular}{|c|c|c|c|c|c|c|c|c|}
\hline \multirow[b]{2}{*}{$\begin{array}{l}\text { PV Panel Unit } \\
\text { Cost }(\text { USD/m²) }\end{array}$} & \multicolumn{4}{|c|}{ Mono-SI Solar Panel } & \multicolumn{4}{|c|}{ Poly-SI Solar Panel } \\
\hline & $\begin{array}{l}A_{P V} \\
\left(\mathrm{~m}^{2}\right)\end{array}$ & $N_{B S}$ & $\begin{array}{l}\text { TNAC } \\
\text { (USD) }\end{array}$ & $\begin{array}{c}\text { LLSP } \\
(\%)\end{array}$ & $\begin{array}{l}A_{P V} \\
\left(\mathrm{~m}^{2}\right)\end{array}$ & $N_{B S}$ & $\begin{array}{l}\text { TNAC } \\
\text { (USD) }\end{array}$ & $\begin{array}{c}\text { LLSP } \\
(\%)\end{array}$ \\
\hline 80 & 110.2 & 1092 & 102,862 & 1.9607 & 146.9 & 1089 & 103,192 & 1.9796 \\
\hline 100 & 110.6 & 1093 & 103,219 & 1.9014 & 146.9 & 1090 & 103,630 & 1.9722 \\
\hline 120 & 111 & 1092 & 103,384 & 1.8342 & 147 & 1088 & 103,777 & 1.9644 \\
\hline 150 & 110.3 & 1090 & 103,586 & 1.9523 & 147.1 & 1096 & 105,047 & 1.9502 \\
\hline 180 & 110.7 & 1093 & 104,261 & 1.8877 & 147.6 & 1096 & 105,580 & 1.8811 \\
\hline 210 & 110.1 & 1093 & 104,686 & 1.9924 & 147.4 & 1096 & 106,167 & 1.9078 \\
\hline 250 & 110.5 & 1093 & 105,166 & 1.9068 & 147 & 1096 & 106,772 & 1.9543 \\
\hline 300 & 110.1 & 1094 & 105,889 & 1.9774 & 147.1 & 1096 & 107,637 & 1.9502 \\
\hline 350 & 110.2 & 1090 & 106,173 & 1.9687 & 147.2 & 1096 & 108,509 & 1.9296 \\
\hline 400 & 110.6 & 1090 & 106,823 & 1.9605 & 147.1 & 1099 & 109,639 & 1.9464 \\
\hline 450 & 110.1 & 1092 & 107,642 & 1.9909 & 147.5 & 1096 & 110,255 & 1.8914 \\
\hline 500 & 110.7 & 1094 & 108,515 & 1.8782 & 147.4 & 1093 & 110,841 & 1.9034 \\
\hline
\end{tabular}




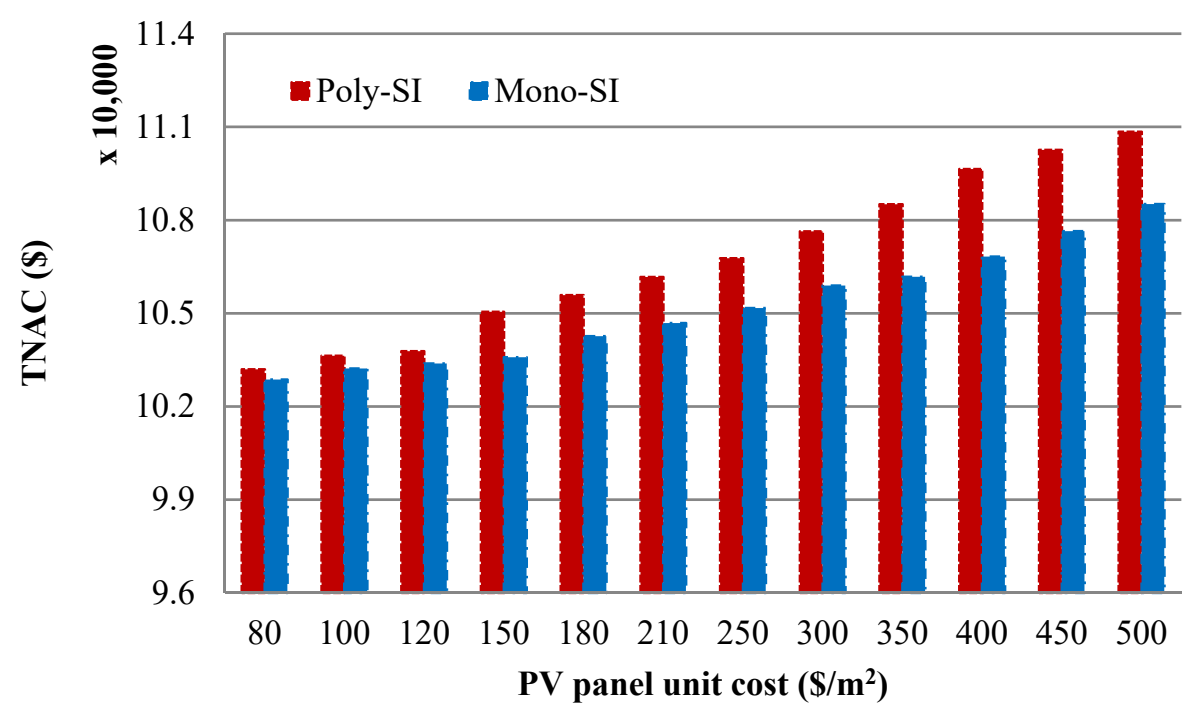

Figure 11. TNAC of the hybrid scheme vs. PV panel unit cost in the optimal situation for different types of solar panels.

The optimal configurations of the hybrid photovoltaic-battery system for Mono-SI solar panels based on different PV efficiency are reported in Table 7. In PV efficiency equal to $20 \%$, the optimal values of $A_{P V}, N_{B S}$, TNAC, and LLSP of the hybrid system are $110.1 \mathrm{~m}^{2}, 1093$, USD 104,686 , and $1.9924 \%$, respectively. In the PV efficiency equal to $16.5 \%$, the optimal values of TNAC, $A_{P V}, N_{B S}$, and LLSP of the hybrid system are USD 105,545, $133.8 \mathrm{~m}^{2}, 1094$, and $1.9354 \%$, respectively. It is observed that by reducing PV efficiency from $20 \%$ to $16.5 \%$, the value of TNAC and $A_{P V}$ increase to USD 859 and $21.5 \%$, respectively, and by increasing the PV efficiency from $20 \%$ to $24 \%$, the value of TNAC, $A_{P V}$, and $N_{B S}$ decrease to $2.3 \%, 16.6 \%$, and $1.8 \%$, respectively. The optimal areas of the PV panel of the hybrid scheme vs. PV efficiency in the optimal situation for the Mono-SI solar panel are presented in Figure 12. It is observed that by increasing the PV efficiency from $16.5 \%$ to $24 \%$, the optimal value of $A_{P V}$ is decreased from $133.8 \mathrm{~m}^{2}$ to $91.8 \mathrm{~m}^{2}$.

Table 7. The optimal configuration of the hybrid photovoltaic-battery scheme for Mono-SI solar panel based on different PV efficiency.

\begin{tabular}{ccccc}
\hline PV Efficiency (\%) & $\boldsymbol{A}_{\boldsymbol{P V}}\left(\mathbf{m}^{\mathbf{2}}\right)$ & $\boldsymbol{N}_{\boldsymbol{B S}}$ & TNAC (USD) & LLSP (\%) \\
\hline 16.5 & 133.8 & 1094 & 105,545 & 1.9354 \\
\hline 18 & 122.6 & 1095 & 105,277 & 1.9350 \\
\hline 20 & 110.1 & 1093 & 104,686 & 1.9924 \\
\hline 22 & 100.1 & 1074 & 102,619 & 1.9999 \\
\hline 24 & 91.8 & 1073 & 102,261 & 1.9990 \\
\hline
\end{tabular}

The optimal configurations of the hybrid photovoltaic-battery system for Poly-SI solar panels based on different PV efficiencies are presented in Table 8. In PV panel efficiencies equal to $15 \%$, the optimal values of TNAC and LLSP of the hybrid system are USD 103,777 and $1.9644 \%$, respectively. In addition, the optimal values of $A_{P V}$ and $N_{B S}$ are $147 \mathrm{~m}^{2}$ and 1088, respectively. In the PV efficiency equal to $12 \%$ and $18 \%$, the optimal value of the TNAC of the hybrid system is USD 106,386and USD 102,247, respectively. It is found that by reducing PV efficiency from $15 \%$ to $12 \%$, the value of TNAC increases to $2.5 \%$, and by increasing the PV efficiency from 15 to $18 \%$, the value of TNAC decreases to $1.5 \%$. Figure 12 shows the area of the PV panel of the hybrid scheme vs. PV efficiency in the optimal condition for the Poly-SI solar panel. It is found that by reducing PV efficiency from $18 \%$ to $12 \%$, the value of $A_{P V}$ is increased from $122.4 \mathrm{~m}^{2}$ to $183.6 \mathrm{~m}^{2}$. 


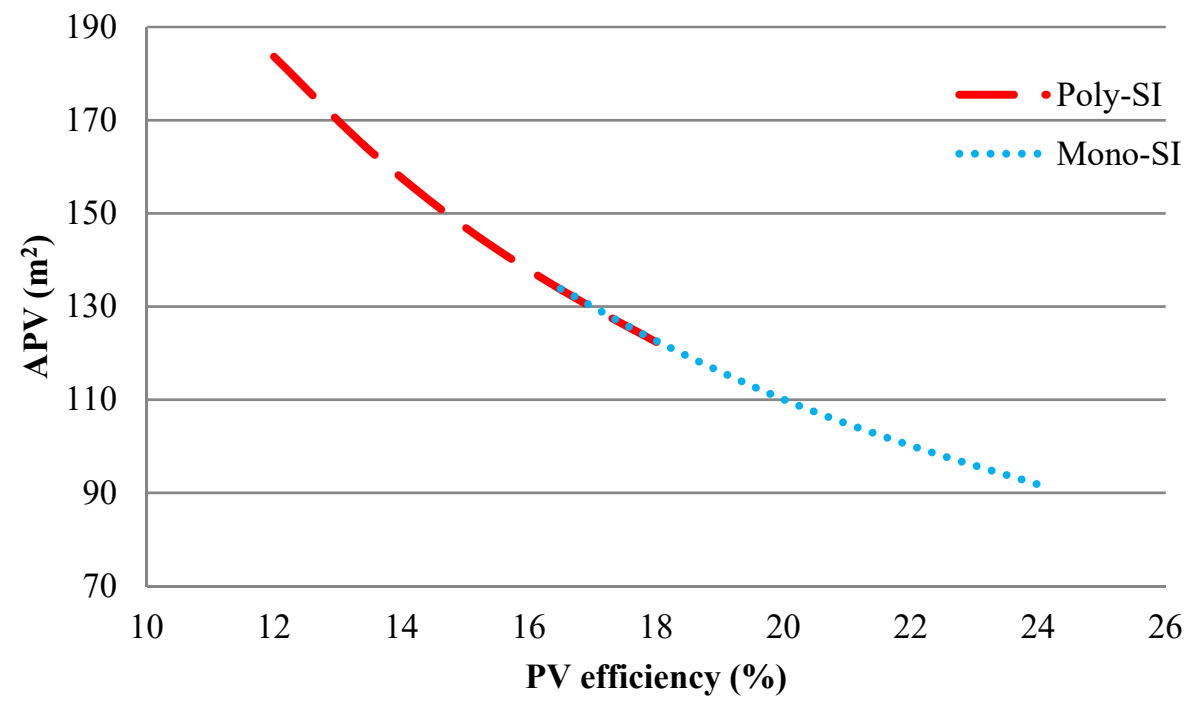

Figure 12. Area of the PV panel of the hybrid scheme vs. PV efficiency in the optimal condition for Mono-SI and Poly-SI solar panels.

Table 8. The optimal configuration of the hybrid photovoltaic-battery scheme for Poly-SI solar panel based on different PV efficiency.

\begin{tabular}{ccccc}
\hline PV Efficiency (\%) & $\left.\boldsymbol{A}_{\boldsymbol{P V}} \mathbf{( m}^{\mathbf{2}}\right)$ & $\boldsymbol{N}_{\boldsymbol{B S}}$ & TNAC (USD) & LLSP (\%) \\
\hline 12 & 183.6 & 1108 & 106,386 & 1.9514 \\
\hline 13.5 & 163.5 & 1104 & 105,595 & 1.9191 \\
\hline 15 & 147 & 1088 & 103,777 & 1.9644 \\
\hline 16.5 & 133.66 & 1087 & 103,403 & 1.9624 \\
\hline 18 & 122.4 & 1077 & 102,247 & 1.9972 \\
\hline
\end{tabular}

\section{Conclusions}

In this study, a new optimization approach, global dynamic harmony search, is presented for optimal sizing of a hybrid photovoltaic-battery scheme to find minimum cost and reliable supply of electricity. The optimal sizing of the stand-alone hybrid scheme is determined by applying two types of PV panels (monocrystalline and polycrystalline). The performance optimizations by the proposed algorithm are compared with the original global dynamic harmony search, original harmony search, and simulated annealing to determine the effectiveness of the suggested optimization method. The effect of initial costs and efficiency of monocrystalline and polycrystalline solar panels on the optimization of hybrid systems is analyzed. The results show that, based on different indices (Best, Worst, Mean, Std., and Meantime), the GDHS-I algorithm has superior robustness to the GDHS, HS, and SA methods due to its optimal values for the TNAC and LLSP. As a result, by increasing the Mono-SI solar panel and Poly-SI solar panel unit costs, the TNAC of the hybrid system are increased. In addition, by increasing Poly-SI solar panel efficiency from $12 \%$ to $18 \%$, the optimal values of PV areas and the amount of battery storage decrease to $3.9 \%$ and $2.8 \%$, respectively. Moreover, by increasing Mono-SI solar panel efficiency from $16.5 \%$ to $24 \%$, the optimal value of PV areas and the amount of battery storage decreases to $3.1 \%$ and $2 \%$, respectively.

Author Contributions: Conceptualization, J.L., L.M. and A.M.; methodology, J.L. and A.M.; software, J.L. and L.M.; validation, J.L., L.M., and A.M.; formal analysis, A.M. and R.G.; investigation, F.P.; resources, J.L. and A.M.; data curation, A.M., F.P. and R.G.; writing-original draft preparation, J.L., L.M. and A.M.; writing-review and editing, A.M., F.P. and R.G.; supervision, A.M.; project administration, A.M. All authors have read and agreed to the published version of the manuscript. 
Funding: This research received no external funding.

Institutional Review Board Statement: Not applicable.

Informed Consent Statement: Not applicable.

Data Availability Statement: Not applicable.

Conflicts of Interest: The authors declare no conflict of interest.

\section{References}

1. Peng, X.; Liu, Z.; Jiang, D. A review of multiphase energy conversion in wind power generation. Renew. Sustain. Energy Rev. 2021, 147, 111172. [CrossRef]

2. Zhang, L.; Wang, X.; Zhang, Z.; Cui, Y.; Ling, L.; Cai, G. An adaptative control strategy for interfacing converter of hybrid microgrid based on improved virtual synchronous generator. IET Renew. Power Gener. 2021, 1-13. [CrossRef]

3. Maleki, A.; Rosen, M.; Pourfayaz, F. Optimal operation of a grid-connected hybrid renewable energy system for residential applications. Sustainability 2017, 9, 1314. [CrossRef]

4. Sun, Y.; Yang, Y.; Shi, X.L.; Suo, G.; Chen, H.; Hou, X.; Chen, Z.G. Self-standing film assembled using SnS-Sn/multiwalled carbon nanotubes encapsulated carbon fibers: A po-tential large-scale production material for ultra-stable sodium-ion battery anodes. ACS Appl. Mater. Interfaces 2021, 13, 28359-28368. [CrossRef]

5. Tan, L.; Sun, Y.; Wei, C.; Tao, Y.; Tian, Y.; An, Y.; Feng, J. Design of Robust, Lithiophilic, and Flexible Inorganic-Polymer Protective Layer by Separator Engi-neering Enables Dendrite-Free Lithium Metal Batteries with LiNi0. 8Mn0. 1Co0. 1O2 Cathode. Small 2021, 17, 2007717. [CrossRef] [PubMed]

6. Zhang, X.; Tang, Y.; Zhang, F.; Lee, C.-S. A Novel Aluminum-Graphite Dual-Ion Battery. Adv. Energy Mater. 2016, 6, 1502588. [CrossRef]

7. Tong, X.; Zhang, F.; Ji, B.; Sheng, M.; Tang, Y. Carbon-Coated Porous Aluminum Foil Anode for High-Rate, Long-Term Cycling Stability, and High Energy Density Dual-Ion Batteries. Adv. Mater. 2016, 28, 9979-9985. [CrossRef] [PubMed]

8. Ji, B.; Zhang, F.; Song, X.; Tang, Y. A novel potassium-ion-based dual-ion battery. Adv. Mater. 2017, 29, 1700519. [CrossRef] [PubMed]

9. Wang, M.; Jiang, C.; Zhang, S.; Song, X.; Tang, Y.; Cheng, H.-M. Reversible calcium alloying enables a practical room-temperature rechargeable calcium-ion battery with a high discharge voltage. Nat. Chem. 2018, 10, 667-672. [CrossRef]

10. Mu, S.; Liu, Q.; Kidkhunthod, P.; Zhou, X.; Wang, W.; Tang, Y. Molecular grafting towards high-fraction active nanodots implanted in N-doped carbon for sodium dual-ion batteries. Natl. Sci. Rev. 2020, 8, 178. [CrossRef] [PubMed]

11. Yan, W.; Liang, K.; Chi, Z.; Liu, T.; Cao, M.; Fan, S.; Xu, T.; Liu, T.; Su, J. Litchi-like structured MnCo2S4@C as a high capacity and long-cycling time anode for lithium-ion batteries. Electrochim. Acta 2021, 376, 138035. [CrossRef]

12. Chauhan, A.; Upadhyay, S.; Khan, M.; Hussain, S.; Ustun, T.S. Performance Investigation of a Solar Photovoltaic/Diesel Generator Based Hybrid System with Cycle Charging Strategy Using BBO Algorithm. Sustainability 2021, 13, 8048. [CrossRef]

13. Kiros, S.; Khan, B.; Padmanaban, S.; Haes Alhelou, H.; Leonowicz, Z.; Mahela, O.P.; Holm-Nielsen, J.B. Development of Stand-Alone Green Hybrid System for Rural Areas. Sustainability 2020, 12, 3808. [CrossRef]

14. Rezk, H.; Alamri, B.; Aly, M.; Fathy, A.; Olabi, A.G.; Abdelkareem, M.A.; Ziedan, H.A. Multicriteria Decision-Making to Determine the Optimal Energy Management Strategy of Hybrid PV-Diesel Battery-Based Desalination System. Sustainability 2021, 13, 4202. [CrossRef]

15. Choi, Y.-J.; Oh, B.-C.; Acquah, M.A.; Kim, D.-M.; Kim, S.-Y. Optimal Operation of a Hybrid Power System as an Island Microgrid in South-Korea. Sustainability 2021, 13, 5022. [CrossRef]

16. Taraba, M.; Adamec, J.; Danko, M.; Drgona, P.; Urica, T. Properties measurement of the thin film solar panels under adverse weather conditions. Transp. Res. Procedia 2019, 40, 535-540. [CrossRef]

17. Symeonidou, M.M.; Zioga, C.; Papadopoulos, A.M. Life cycle cost optimization analysis of battery storage system for residential photovoltaic panels. J. Clean. Prod. 2021, 309, 127234. [CrossRef]

18. Karamov, D.N.; Suslov, K.V. Structural optimization of autonomous photovoltaic systems with storage battery replacements. Energy Rep. 2021, 7, 349-358. [CrossRef]

19. Bhayo, B.A.; Al-Kayiem, H.H.; Gilani, S.I.; Ismail, F.B. Power management optimization of hybrid solar photovoltaic-battery integrated with pumped-hydro-storage system for standalone electricity generation. Energy Convers. Manag. 2020, 215, 112942. [CrossRef]

20. Anoune, K.; Ghazi, M.; Bouya, M.; Laknizi, A.; Ghazouani, M.; Abdellah, A.B.; Astito, A. Optimization and techno-economic analysis of photovoltaic-wind-battery based hybrid system. J. Energy Storage 2020, 32, 101878. [CrossRef]

21. Ridha, H.M.; Gomes, C.; Hazim, H.; Ahmadipour, M. Sizing and implementing off-grid stand-alone photovoltaic/battery systems based on multi-objective optimization and techno-economic (MADE) analysis. Energy 2020, 207, 118163. [CrossRef]

22. Khan, A.; Javaid, N. Jaya Learning-Based Optimization for Optimal Sizing of Stand-Alone Photovoltaic, Wind Turbine, and Battery Systems. Engineering 2020, 6, 812-826. [CrossRef]

23. Bukar, A.L.; Tan, C.W.; Lau, K.Y. Optimal sizing of an autonomous photovoltaic/wind/battery/diesel generator microgrid using grasshopper optimization algorithm. Sol. Energy 2019, 188, 685-696. [CrossRef]

24. Fodhil, F.; Hamidat, A.; Nadjemi, O. Potential, optimization and sensitivity analysis of photovoltaic-diesel-battery hybrid energy system for rural electrification in Algeria. Energy 2019, 169, 613-624. [CrossRef] 
25. Koskela, J.; Rautiainen, A.; Järventausta, P. Using electrical energy storage in residential buildings-Sizing of battery and photovoltaic panels based on electricity cost optimization. Appl. Energy 2019, 239, 1175-1189. [CrossRef]

26. Tu, T.; Rajarathnam, G.P.; Vassallo, A.M. Optimization of a stand-alone photovoltaic-wind-diesel-battery system with multilayered demand scheduling. Renew. Energy 2019, 131, 333-347. [CrossRef]

27. Kazem, H.A.; Khatib, T.; Sopian, K. Sizing of a standalone photovoltaic/battery system at minimum cost for remote housing electrification in Sohar, Oman. Energy Build. 2013, 61, 108-115. [CrossRef]

28. Dai, Q.; Liu, J.; Wei, Q. Optimal photovoltaic/battery energy storage/electric vehicle charging station design based on multi-agent particle swarm optimization algorithm. Sustainability 2019, 11, 1973. [CrossRef]

29. Cai, W.; Li, X.; Maleki, A.; Pourfayaz, F.; Rosen, M.A.; Nazari, M.A.; Bui, D.T. Optimal sizing and location based on economic parameters for an off-grid application of a hybrid system with photovoltaic, battery and diesel technology. Energy 2020, 201, 117480. [CrossRef]

30. Maleki, A.; Nazari, M.A.; Pourfayaz, F. Harmony search optimization for optimum sizing of hybrid solar schemes based on battery storage unit. Energy Rep. 2020, 6, 102-111. [CrossRef]

31. Alshammari, N.; Asumadu, J. Optimum unit sizing of hybrid renewable energy system utilizing harmony search, Jaya and particle swarm optimization algorithms. Sustain. Cities Soc. 2020, 60, 102255. [CrossRef]

32. Chauhan, A.; Saini, R. Discrete harmony search based size optimization of integrated renewable energy system for remote rural areas of Uttarakhand state in India. Renew. Energy 2016, 94, 587-604. [CrossRef]

33. Elattar, E.E. Modified harmony search algorithm for combined economic emission dispatch of microgrid incorporating renewable sources. Energy 2018, 159, 496-507. [CrossRef]

34. Liu, C.; Abdulkareem, S.S.; Rezvani, A.; Samad, S.; Aljojo, N.; Foong, L.K.; Nishihara, K. Stochastic scheduling of a renewablebased microgrid in the presence of electric vehicles using modified harmony search algorithm with control policies. Sustain. Cities Soc. 2020, 59, 102183. [CrossRef]

35. Sheng, W.; Liu, K.-Y.; Liu, Y.; Ye, X.; He, K. Reactive power coordinated optimisation method with renewable distributed generation based on improved harmony search. IET Gener. Transm. Distrib. 2016, 10, 3152-3162. [CrossRef]

36. Bakelli, Y.; Hadj Arab, A.; Azoui, B. Optimal sizing of photovoltaic pumping system with water tank storage using LPSP concept. Sol. Energy 2011, 85, 288-294. [CrossRef]

37. Maleki, A. Design and optimization of autonomous solar-wind-reverse osmosis desalination systems coupling battery and hydrogen energy storage by an improved bee algorithm. Desalination 2018, 435, 221-234. [CrossRef]

38. Belfkira, R.; Zhang, L.; Barakat, G. Optimal sizing study of hybrid wind/PV/diesel power generation unit. Sol. Energy 2011, 85, 100-110. [CrossRef]

39. Ogunjuyigbe, A.; Ayodele, T.; Akinola, O. Optimal allocation and sizing of PV/Wind/Split-diesel/Battery hybrid energy system for minimizing life cycle cost, carbon emission and dump energy of remote residential building. Appl. Energy 2016, 171, 153-171. [CrossRef]

40. Caballero, F.; Sauma, E.; Yanine, F. Business optimal design of a grid-connected hybrid PV (photovoltaic)-wind energy system without energy storage for an Easter Island's block. Energy 2013, 61, 248-261. [CrossRef]

41. Samy, M.; Barakat, S.; Ramadan, H. Techno-economic analysis for rustic electrification in Egypt using multi-source renewable energy based on PV/wind/FC. Int. J. Hydrogen Energy 2019, 45, 11471-11483. [CrossRef]

42. Sarhan, A.; Hizam, H.; Mariun, N.; Ya'acob, M. An improved numerical optimization algorithm for sizing and configuration of standalone photo-voltaic system components in Yemen. Renew. Energy 2019, 134, 1434-1446. [CrossRef]

43. Geem, Z.W. Size optimization for a hybrid photovoltaic-wind energy system. Int. J. Electr. Power Energy Syst. 2012, 42, 448-451. [CrossRef]

44. Geem, Z.W.; Kim, J.H.; Loganathan, G.V. A new heuristic optimization algorithm: Harmony search. Simulation 2001, 76, 60-68. [CrossRef]

45. Maleki, A.; Pourfayaz, F. Sizing of stand-alone photovoltaic/wind/diesel system with battery and fuel cell storage devices by harmony search algorithm. J. Energy Storage 2015, 2, 30-42. [CrossRef]

46. Khalili, M.; Kharrat, R.; Salahshoor, K.; Sefat, M.H. Global dynamic harmony search algorithm: GDHS. Appl. Math. Comput. 2014, 228, 195-219. [CrossRef]

47. Zhang, W.; Maleki, A.; Pourfayaz, F.; Shadloo, M.S. An artificial intelligence approach to optimization of an off-grid hybrid wind/hydrogen system. Int. J. Hydrogen Energy 2021, 46, 12725-12738. [CrossRef]

48. Geem, Z.W.; Yoon, Y. Harmony search optimization of renewable energy charging with energy storage system. Int. J. Electr. Power Energy Syst. 2017, 86, 120-126. [CrossRef]

49. Ekren, O.; Ekren, B.Y. Size optimization of a PV/wind hybrid energy conversion system with battery storage using simulated annealing. Appl. Energy 2010, 87, 592-598. [CrossRef]

50. Zhang, W.; Maleki, A.; Rosen, M.A. A heuristic-based approach for optimizing a small independent solar and wind hybrid power scheme incorporating load forecasting. J. Clean. Prod. 2019, 241, 117920. [CrossRef]

51. Available online: http://www.wholesalesolar.com/ (accessed on 9 January 2021).

52. Available online: https://www.solaris-shop.com/solarworld-sunmodule-plus-sw285-mono-285w-solar-panel/ (accessed on 9 January 2021).

53. Available online: https://www.solaris-shop.com/solarworld-poly-pro-sw260-poly-260w-solar-panel/ (accessed on 9 January 2021). 